Check for updates

Cite this: Chem. Commun., 2017, 53,9085

Received 6th June 2017,

Accepted 17th July 2017

DOI: $10.1039 / c 7 c c 04380 e$

rsc.li/chemcomm

\section{Pushing the limits of automated glycan assembly: synthesis of a 50 mer polymannoside $\dagger$}

\author{
K. Naresh, (D) ${ }^{a b}$ F. Schumacher, (D) ${ }^{a b}$ H. S. Hahm (D) ${ }^{a b}$ and P. H. Seeberger (D) $\star^{a b}$
}

\begin{abstract}
Automated glycan assembly (AGA) enables rapid access to oligosaccharides. The overall length of polymers created via automated solid phase synthesis depends on very high yields at every step to obtain full length products. The synthesis of long polymers serves as the ultimate test of the efficiency and reliability of synthetic processes. A series of Man-(1 $\rightarrow 6)-\alpha$-Man linked oligosaccharides up to a 50mer, the longest synthetic sequence yet assembled from monosaccharides, has been realized via a 102 step synthesis. We identified a suitable mannose building block and applied a capping step in the final five AGA cycles to minimize $(n-1)$ deletion sequences that are otherwise difficult to remove by HPLC.
\end{abstract}

Carbohydrates play important structural roles and are key to many biological events. ${ }^{1}$ Unlike peptides ${ }^{2}$ and nucleotides ${ }^{3}$ for which sequences of greater than 50 monomer units can now be rapidly assembled by commercial synthesizers, the chemical synthesis of polysaccharides is still challenging due to inherent structural complexities requiring stereo- and regio-control during glycosylation. Though immense progress has been made in the development of chemical glycosylation methods, reports of synthetic polysaccharides longer than 18mers are few in number. ${ }^{4,5}$ The syntheses of a mycobacterial arabinogalactan 92mer, a heparin-related 40mer, and a mycobacterial mannose capped arabinomannan 21 mer were accomplished using block couplings. ${ }^{5}$ From a biomaterials perspective, it is necessary to overcome these synthetic limitations to enable the exploration of the properties of chemically well-defined and pure carbohydrates. As naturally derived saccharide-based materials have served as scaffolds for stem cell based tissue engineering, ${ }^{6}$ the relatively facile automated synthesis of peptides and oligonucleotides has enabled the identification of hybrid hydrogels for bioprinting. ${ }^{7}$

\footnotetext{
${ }^{a}$ Max Planck Institute of Colloids and Interfaces, Department of Biomolecular Systems, Am Mühlenberg 1, 14476 Potsdam-Golm, Germany.

E-mail: seeberger@mpikg.mpg.de

${ }^{b}$ Freie Universität Berlin, Department of Chemistry and Biochemistry,

Arnimallee 22, 14195 Berlin, Germany

$\dagger$ Electronic supplementary information (ESI) available: Experimental details and full spectroscopic data for all new compounds. See DOI: 10.1039/c7cc04380e
}

Solid-phase automated glycan assembly (AGA) $)^{8,9}$ of polysaccharides is an evolving technique that has enabled rapid access to complex yet well-defined oligosaccharides such as glycosaminoglycans (GAGs), bacterial cell wall antigens, and plant polysaccharides. The longest synthetic polysaccharide prepared by AGA to date is a 30mer oligomannoside. ${ }^{10}$ Though AGA has proven to be versatile, all aspects of the process require improvement and the methodology is still developing. We present a systematic study of Man-(1 $\rightarrow 6)-\alpha$-Man oligomers that addresses building block reactivity and product purification and culminates in the 102 step synthesis of a 50mer polysaccharide.

The key to successful AGA is the identification of building blocks that enable high yielding coupling reactions and facilitate downstream purification. To select the best building block, we designed three differentially protected thiomannoside monomers (1-3, Scheme 1) for the synthesis of long linear polysaccharides containing Man-( $1 \rightarrow 6)-\alpha$-Man linkages. Although the AGA

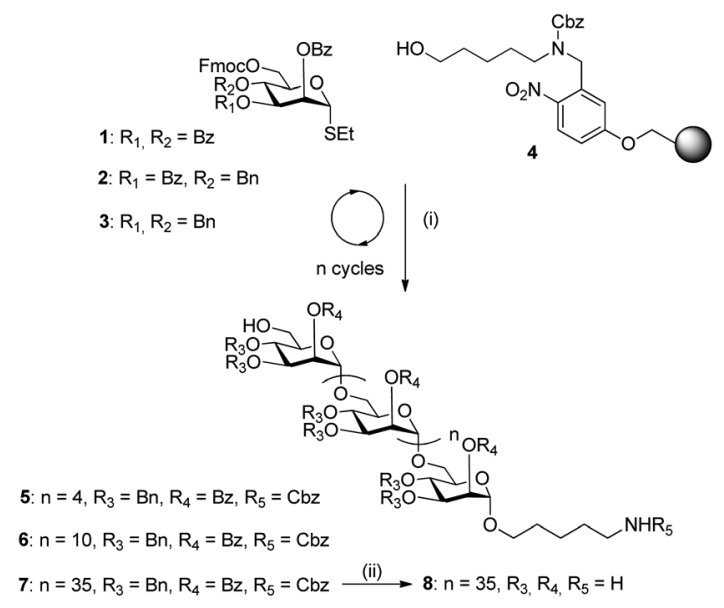

Scheme 1 AGA of mannose oligomers. (i) (a) glycosylation: 3, NIS, TfOH, $-40{ }^{\circ} \mathrm{C}$ ramped up immediately to $-20^{\circ} \mathrm{C}$, then $20 \mathrm{~min}, \mathrm{CH}_{2} \mathrm{Cl}_{2}$, dioxane; (b) Fmoc deprotection: $\mathrm{Et}_{3} \mathrm{~N}, \mathrm{DMF}, \mathrm{rt}, 5 \mathrm{~min}$, repeated twice; (c) acid wash: TMSOTf, $\mathrm{CH}_{2} \mathrm{Cl}_{2},-20^{\circ} \mathrm{C}$; (d) post-automation photocleavage: $h \nu, \mathrm{CH}_{2} \mathrm{Cl}_{2}$, rt. (ii) (a) $\mathrm{NaOMe} / \mathrm{MeOH}$, rt; (b) $\mathrm{Pd} / \mathrm{C}, \mathrm{H}_{2}, \mathrm{MeOH} / \mathrm{THF} / \mathrm{AcOH}$. 
synthesis of a mannose 30mer reported by us in 2013 relied on a glycosyl phosphate donor, ${ }^{10}$ the present study utilizes thioglycoside donors because these can be obtained in fewer synthetic steps and they are stable under the conditions required to generate various building blocks.

Monomers 1-3 carry a permanent benzoyl group at the $\mathrm{C} 2$ position to ensure $\alpha$-selectivity (i.e., 1,2-trans-glycosidic linkages) through neighboring group participation, and a temporary Fmoc carbonate protecting group is present at the C6 position for chain elongation. The C3 and C4 hydroxyl groups are protected with arming ${ }^{11,12}$ benzyl ethers (3), disarming ${ }^{13}$ benzoyl esters $(1){ }^{7}$ or a combination of the two $(2)^{14}(\mathrm{ESI} \dagger)$.

Trisaccharides were synthesized in separate batches on a Merrifield resin equipped with a photo-labile linker (4) to determine the effect of the protecting groups on reactivity and product purification (ESI $\dagger$ ). ${ }^{15}$ Analysis of the synthesis products revealed that building block 3, containing two arming benzyl ether protecting groups, performs best in the synthesis of Man- $(1 \rightarrow 6)-\alpha$-Man oligosaccharides due to both its greater reactivity and the fact that its full length oligosaccharide product is well separated from deletion sequences by HPLC (ESI $\dagger)$.

Linear mannose chains from six (5) to 50 (10) monomer units in length were assembled using building block 3 (Schemes 1 and 2). Employing the conditions developed for the trisaccharide syntheses, each glycosylation step was performed using 6.4 molar equivalents of the building block, based on Fmoc quantification of the initial sugar loading. ${ }^{16}$ The temporary Fmoc group at the C6 position was removed by treatment with triethylamine, and an acid wash with a TMSOTf solution was included prior to the downstream glycosylation to remove traces of water

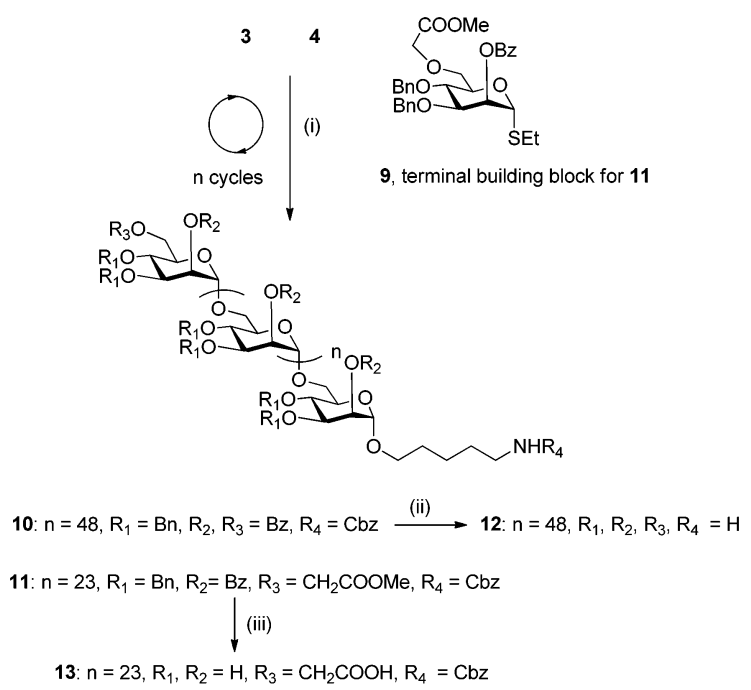

Scheme 2 AGA of mannose oligomers. (i) (a) glycosylation: 3 then 9 (terminal building block for 11 ), $\mathrm{NIS}, \mathrm{TfOH},-40{ }^{\circ} \mathrm{C}$ ramped up immediately to $-20{ }^{\circ} \mathrm{C}$, then $20 \mathrm{~min}, \mathrm{CH}_{2} \mathrm{Cl}_{2}$, dioxane; (b) capping: pyridine, $\mathrm{Ac}_{2} \mathrm{O}$, rt; (c) Fmoc deprotection: $\mathrm{Et}_{3} \mathrm{~N}, \mathrm{DMF}, \mathrm{rt}, 5 \mathrm{~min}$, repeated twice; (d) acid wash: TMSOTf, $\mathrm{CH}_{2} \mathrm{Cl}_{2},-20^{\circ} \mathrm{C}$; (e) post-automation photocleavage: $h \nu, \mathrm{CH}_{2} \mathrm{Cl}_{2}$, rt. (ii) (a) $\mathrm{NaOMe} / \mathrm{MeOH}$, rt; (b) Pd/C, $\mathrm{H}_{2}, \mathrm{MeOH}$ :THF:AcOH. (iii) (a) $\mathrm{NaOMe} /$ $\mathrm{MeOH}, \mathrm{rt}$; (b) $\mathrm{NaOH} / \mathrm{MeOH}, \mathrm{H}_{2} \mathrm{O}$, rt; (c) $\mathrm{Pd} / \mathrm{C}, \mathrm{H}_{2}, \mathrm{MeOH}$ :THF:AcOH; (d) $\mathrm{H}_{2} \mathrm{O}, \mathrm{Et}_{3} \mathrm{~N}, \mathrm{CbzCl}, \mathrm{O}^{\circ} \mathrm{C}$ to rt. and base. Following the automated assembly process, the resin was subjected to UV irradiation using a continuous flow device ${ }^{17}$ to cleave the protected oligosaccharide products from the polymer matrix. Hexasaccharide 5 (13 steps) and dodecasaccharide 6 (25 steps) were readily purified from all deletion sequences by normal phase HPLC and were obtained in 50\% and 38\% yield, respectively, based on resin loading with the first sugar. Previously, the automated assembly of a dodecamannoside ${ }^{10}$ from building block 1 had yielded a product mixture that could not be purified by normal phase HPLC and mandated a special catch-release technique for purification. In contrast, dodecasaccharide 6 assembled from building block 3 is easily purified by normal phase HPLC, demonstrating the importance of protecting group selection for facile oligomer purification.

Separation of the desired product from the immediate deletion sequence (i.e., $n$ vs. $n-1$ ) by HPLC becomes progressively more challenging as the chain length increases. For example, 37 mer 7 co-elutes with the $36 \mathrm{mer}$, precluding purification by HPLC (ESI $\dagger$ ). In addition, the proportion of the $n-1$ deletion sequence also increases with chain length (Table 1). To address separation problems and incomplete conversion, an additional acetylation, or capping step, similar to that commonly used in oligonucleotide and sometimes in peptide synthesis, was employed throughout the assembly of 50mer 10 (Scheme 2 and Table 1). The synthetic outcomes of products up to 37 mers (Table 1) illustrate that oligomers of length $n-5$ and shorter can easily be removed from the desired product by HPLC. Thus, in order to eliminate the formation of deletion sequences longer than $n-5$, an additional strategy was employed in the synthesis of 10, namely, introducing a second glycosylation step (6.4 eq. of building block in each coupling step; two coupling steps) in each of the last five elongation cycles (46 to 50). The 50mer 10 is obtained in 5\% overall yield after 102 AGA steps; thus the average step-wise yield is $97.1 \%$ (Table 1 and the ESI $\dagger$ ). Furthermore, the full length product is well resolved by HPLC and easily purified from truncated sequences when utilizing capping and the additional coupling step, as confirmed by MALDI analysis (Fig. 1).

Although capping in each cycle facilitates the purification of 50mer 10, it is time consuming ( $2 \mathrm{~h}$ for each capping step), accounting for half of the synthesis run time. In an attempt to further optimize AGA, as proof of concept, mannose 25mer 11 was synthesized with capping only in the last five elongation cycles (21 to 25 ) and a second coupling step with the glycosyl donor, as described above for 50mer 10, during these final cycles. Thus, the full length bifunctional $25 \mathrm{mer}$ is produced in $28 \%$ overall yield after 52 AGA steps, representing a $97.6 \%$ average step-wise yield, an improvement compared to the 50mer 10 synthesis. The bi-functional polysaccharide obtained from orthogonal building block 9 containing a methyl ester functionality at the C6 position could be used for further synthetic manipulations, such as coupling to other polysaccharides or biomolecules to generate hybrid biomaterials. The overlaid ${ }^{13} \mathrm{C}$ NMR spectra of the polymannosides (Fig. 2) confirm their structural similarities. Syntheses were performed on a $10 \mu \mathrm{mol}$ scale. Routinely AGA is now carried out on $12.5 \mu \mathrm{mol}$ and $25 \mu \mathrm{mol}$ 
Table 1 Summary of AGA methods

\begin{tabular}{|c|c|c|c|c|c|}
\hline Compound number (length) & Glycosylation $^{a}$ & Capping & Total time (h) & Product ratio $n: n-1: n-2$ & Yield $^{b}(\%)$ \\
\hline 5 (6mer) & Cycles 1-6: 6.4 eq. donor & No & 10 & $92: 8: 0$ & 50 \\
\hline 6 (12mer) & Cycles 1-12: 6.4 eq. donor & No & 20 & $87: 13: 0$ & 38 \\
\hline S8 (24mer) & Cycles 1-24: 6.4 eq. donor & No & 40 & $58: 31: 4$ & - \\
\hline 7 (37mer) & Cycles 1-37: 6.4 eq. donor & No & 60 & $50: 50: 0$ & $36^{c}$ \\
\hline 11 (25mer) & $\begin{array}{l}\text { Cycles 1-20: } 6.4 \text { eq. donor } \\
\text { Cycles 21-25: } 2 \times 6.4 \text { eq. } \text { donor }^{d}\end{array}$ & Cycles 21-25 & 50 & - & 28 \\
\hline 10 (50mer) & $\begin{array}{l}\text { Cycles 1-45: } 6.4 \text { eq. donor } \\
\text { Cycles } 46-50: 2 \times 6.4 \text { eq. donor }\end{array}$ & Cycles 1-50 & 250 & - & 5 \\
\hline
\end{tabular}

${ }^{a}$ Building block 3; equivalents based on the Fmoc loading of the first sugar on the resin. ${ }^{b}$ Yield based on Fmoc loading of the first sugar on the resin. ${ }^{c}$ Yield for an inseparable $1: 1$ mixture of 37 mer and 36 mer. ${ }^{d}$ Building block 9 as the terminal group in cycle 25.

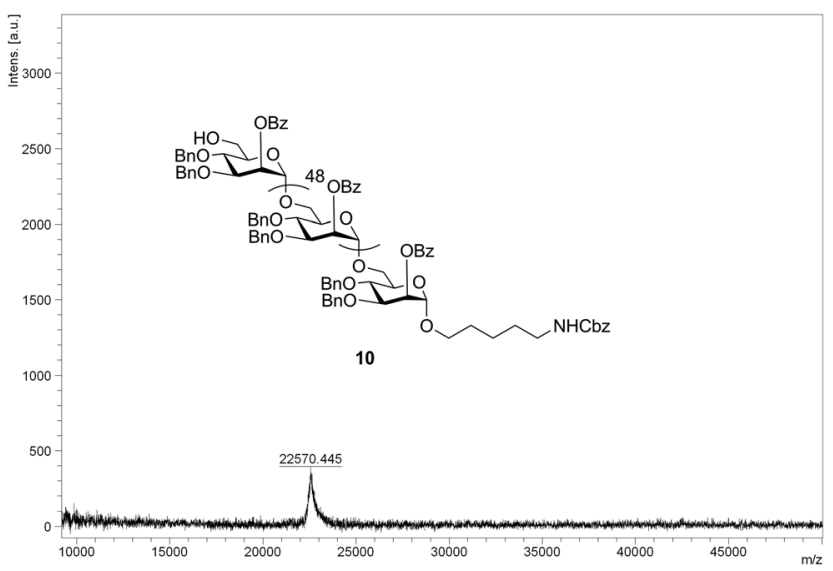

Fig. 1 MALDI-TOF spectrum of protected mannose 50mer 10

scales using preprogramed synthesis cycles. There is no reason why AGA could not be scaled up to a $50-100 \mu \mathrm{mol}$ scale as has been done for oligonucleotide and oligopeptide syntheses. Methodological advances currently under development in our laboratory including improved coupling and capping procedures should make it possible to obtain polysaccharides longer than 100mers in the future.

The mannose 37mer (along with the 36mer impurity) and 50mer were deprotected using Zemplén methanolysis $(\mathrm{NaOMe} / \mathrm{MeOH})$

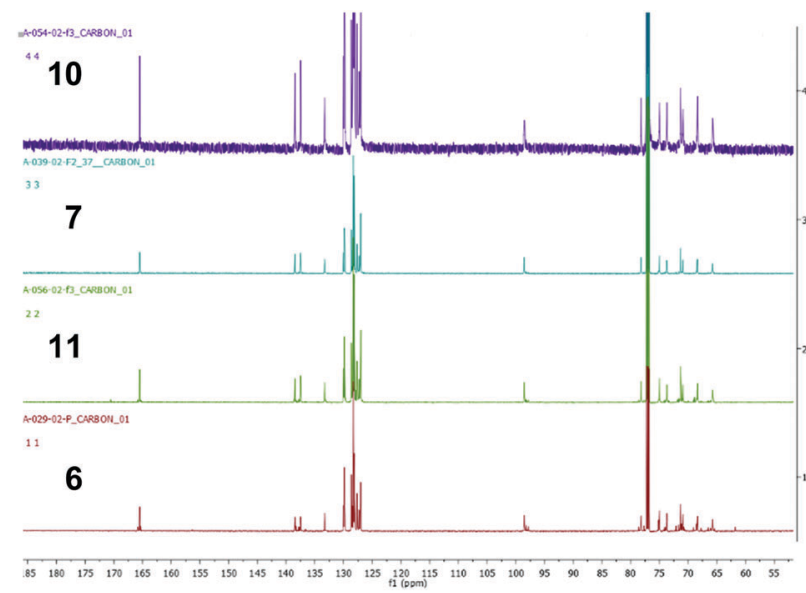

Fig. 2 Overlaid ${ }^{13} \mathrm{C}$ NMR spectra of protected 6 (12mer), 11 (25mer), 7 (37mer) and 10 (50mer).

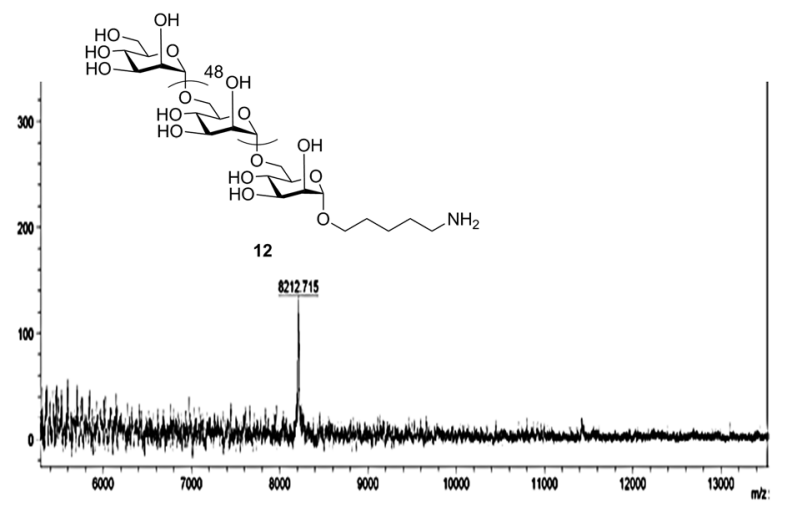

Fig. 3 MALDI-TOF spectrum of deprotected mannose 50mer 12.

to remove ester groups and hydrogenolysis to eliminate benzyl groups in the presence of $\mathrm{Pd} / \mathrm{C}(\mathrm{ESI}+)$. For hydrogenolysis, due to the very large number of benzyl groups, the reaction was carried out for extended periods of time ( 72 to $96 \mathrm{~h}$ ) and/or multiple rounds to ensure completion of the reaction, as confirmed by MALDI analysis (Fig. 3).

In summary, by selecting the best building block in terms of reactivity and downstream purification, mannose chains as long as 50mers were assembled using AGA. Optimal conditions involving capping and an excess of the building block used only in the last five cycles were identified for successful AGA of homo-glycopolymers, with average step-wise yields as high as $97.6 \%$. This process is beginning to enable the procurement of biopolymers for materials applications.

There are no conflicts of interest to declare.

Open Access funding provided by the Max Planck Society.

\section{Notes and references}

1 Essentials of Glycobiology, ed. A. Varki, R. D. Cummings, J. D. Esko, H. H. Freeze, P. Stanley, C. R. Bertozzi, G. W. Hart and M. E. Etzler, Cold Spring Harbor Laboratory Press, Cold Spring Harbor (NY), 2nd edn, 2009; P. H. Seeberger and D. B. Werz, Nature, 2007, 446, 1046; A. Varki, Glycobiology, 1993, 3, 97.

2 E. Atherton and R. C. Sheppard, in Solid-Phase Peptide Synthesis: A Practical Approach, ed. D. Rickwood, B. D. Hames, The Practical Approach Series, IRL Press at Oxford University Press, Oxford, 1989.

3 M. H. Caruthers, Science, 1985, 230, 281.

4 M. Joe, Y. Bai, R. C. Nacario and T. L. Lowary, J. Am. Chem. Soc., 2007, 129, 9885; Y. Matsuzaki, Y. Ito, Y. Nakahara and T. Ogawa, Tetrahedron Lett., 1993, 34, 1061; M. Petitou, P. Duchaussoy, P.-A. Driguez, J.-P. Herault, J.-C. Lormeau and J.-M. Herbert, Bioorg. Med. Chem. Lett., 1999, 9, 1155; V. Pozsgay, Tetrahedron: Asymmetry, 2000, 
11, 151; B. Fraser-Reid, J. Lu, K. N. Jayaprakash and J. C. López, Tetrahedron: Asymmetry, 2006, 17, 2449.

5 Y. Wu, D.-C. Xiong, S.-C. Chen, Y.-S. Wang and X.-S. Ye, Nat. Commun., 2017, 8, DOI: 10.1038/ncomms14851; S. U. Hansen, G. J. Miller, M. J. Cliff, G. C. Jayson and J. M. Gardiner, Chem. Sci., 2015, 6, 6158; M. Islam, G. P. Shinde and S. Hotha, Chem. Sci., 2017, 8, 2033.

6 J. Hu, P. H. Seeberger and J. Yin, Org. Biomol. Chem., 2016, 14, 8648.

7 C. Li, A. Faulkner-Jones, A. R. Dun, J. Jin, P. Chen, Y. Xing, Z. Yang, Z. Li, W. Shu, D. Liu and R. R. Duncan, Angew. Chem., Int. Ed., 2015, 54, 3957.

8 C.-H. Hsu, S.-C. Hung, C.-Y. Wu and C.-H. Wong, Angew. Chem., Int. Ed., 2011, 50, 11872.

9 M. W. Weishaupt, H. S. Hahm, A. Geissner and P. H. Seeberger, Chem. Commun., 2017, 53, 3591.

10 O. Calin, S. Eller and P. H. Seeberger, Angew. Chem., Int. Ed., 2013, 52, 5862.
11 D. R. Mootoo, P. Konradsson, U. Udodong and B. Fraser-Reid, J. Am. Chem. Soc., 1988, 110, 5583.

12 M. Fridman, D. Solomon, S. Yogev and T. Baasov, Org. Lett., 2002, $4,281$.

13 B. Fraser-Reid and J. C. López, Top. Curr. Chem., 2011, 301, 1.

14 H. S. Hahm, M. K. Schlegel, M. Hurevich, S. Eller, F. Schuhmacher, J. Hofmann, K. Pagel and P. H. Seeberger, Proc. Natl. Acad. Sci. U. S. A., 2017, 114, E3385, DOI: 10.1073/pnas.1700141114.

15 S. Eller, M. Collot, J. Yin, H. S. Hahm and P. H. Seeberger, Angew. Chem., Int. Ed., 2013, 52, 5858.

16 M. Gude, J. Ryf and P. D. White, Lett. Pept. Sci., 2002, 9, 203; J. Meienhofer, M. Waki, E. P. Heimer, T. J. Lambros, R. C. Makofske and C. D. Chang, Int. J. Pept. Protein Res., 1979, 13, 35.

17 M. Hurevich, J. Kandasamy, B. M. Ponnappa, D. Kopetzki, T. McQuade and P. H. Seeberger, Org. Lett., 2014, 16, 1794. 